Original Article

\title{
DETERMINATION, ISOLATION, AND IDENTIFICATION OF AUCUBIN AND VERBASCOSIDE IN THE LEAVES OF IRAQI PLANTAGO LANCOLETA L. USING DIFFERENT DETECTING METHODS
}

\author{
HASAN A. KHALAFa, IBRAHIM S. ABBAS ${ }^{b}$, AMANI A. TAWFEEQ $^{c}$, MONTHER F. MAHDId
}

a,b,cDepartment of Pharmacognosy and Medicinal Plants, College of Pharmacy, Mustansiriya University, Baghdad-Iraq, dDepartment of Pharmaceutical Chemistry/pharmacy, Ashur University College, Baghdad-Iraq

Email: hasan.alaa84@yahoo.com

Received: 30 Oct 2018 Revised and Accepted: 31 Dec 2018

\section{ABSTRACT}

Objective: Plantago lanceoleta L. (ribwort plantain) is one of the important medicinal herbs which is widespread fortune available in Iraq, that have a wide range of medicinal properties. The aim of this work was to determine, isolate and identify verbascoside and aucubin in Iraqi $P$. lanceoleta $\mathrm{L}$. by using different chromatographic and spectrometric methods.

Methods: Verbascoside and aucubin were isolated and quantified by preparative TLC, and then they were determined by the high-performance thin-layer chromatography (HPTLC) fingerprinting. Aucubin and catalpol in the plant extract were analyzed by liquid chromatography-mass spectrometry (LC-MS); aucubin and verbascoside that isolated from the plant sample were examined by fourier-transform infrared spectroscopy (FT-IR) and LC-MS, respectively.

Results: The result showed that the Iraqi P. lanceoleta L. contains 1.74 percent (verbascoside) and 0.24 percent (aucubin) of dry powdered leaves. Each TLC-isolated compound showed a single spot on the HPTLC plate, which give an idea about the purity of the isolated compound. Aucubin (with catalpol) and verbascoside both are detected by LC-MS in different ionization mode. Many functional groups were identified in the TLC-isolated aucubin by FT-IR.

Conclusion: The Iraqi P. lanceoleta L. showed a high content of verbasoside, and it is a very rich source for this compound, which can be easily isolated by TLC and subjected to many pharmacological studies. The extract of the young leaves of this plant gave a little amount of aucubin, and it is easy to obtain a higher content from the older leaves.

Keywords: Plantago lanceoleta L., Ribwort plantain, Verbascoside, Aucubin

(C) 2019 The Authors. Published by Innovare Academic Sciences Pvt Ltd. This is an open access article under the CC BY license (http://creativecommons.org/licenses/by/4.0/) DOI: http://dx.doi.org/10.22159/ijpps.2019v11i2.30566

\section{INTRODUCTION}

Plantago lanceoleta L. is a flowering plant species of the Plantaginaceae family; the most famous names of this species are ribwort plantain and English plantain which is commonly known in Iraq as sagittal lamb's tongue. Ribwort is a communal, perennial wild plant of arable grounds and grasslands suitable for planting [1].

Ribwort plantain is plentiful throughout Eurasia; it is moderately resistant to the drought and can be cultivated in any relatively fertile soil under sunshine, also seen in very deprived lands and characterized by erect, straight leaves that sheltered with soft minute hairs that reach up to about 17 inches long while flowers set as condensed spikes on the top of the stalks as shown in (fig. 1) [2, 3].

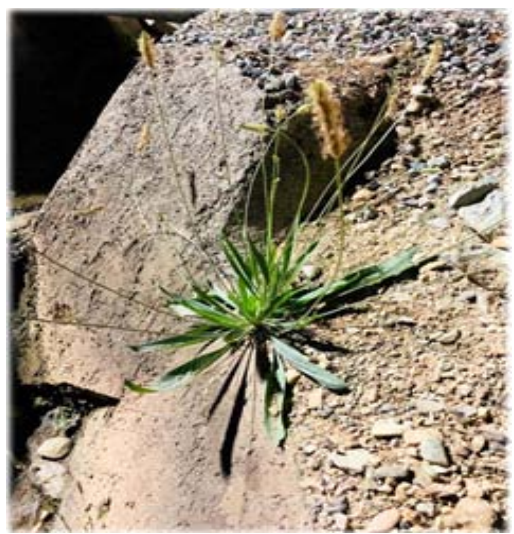

Fig. 1: Iraqi P. lanceoleta L. grown onto the sidewalk
P. lanceolata L. has a monograph in British and European Pharmacopoeia and European scientific cooperative on phytotherapy (ESCOP) [4]. Ribwort plantain is rich in many active constituents, including: iridoid glycosides (aucubin and catalpol) [5], tannins [6] phenylethanoid-phenylpropanoid glycosides (e.g. verbascoside) [7], mucilages [8], flavonoids (apigenin and luteolin) [9], coumarins (esculetin) [10], saponins and volatile compounds $[4,11]$

Iridoid glycosides that found in the ribwort plantain considered as a group of the most important secondary metabolites, and also as chemotaxonomic markers for Plantago spp [12]; aucubin is one of the major molecules found in ribwort plantain; the aucubin concentration in ribwort plantain becomes higher as the leaves get older [13]. It plays many important roles in the medicinal effects of ribwort plantain that include its hepatoprotective [14], pancreasprotective [15], antiarthritic [16], spasmolytic [17], collagen synthesis promoting effects [18], neuroprotective and antiatherogenic [19]; both aucubin and catalpol (fig. 2) play important role in neuroprotection against many pathological disorders [20]
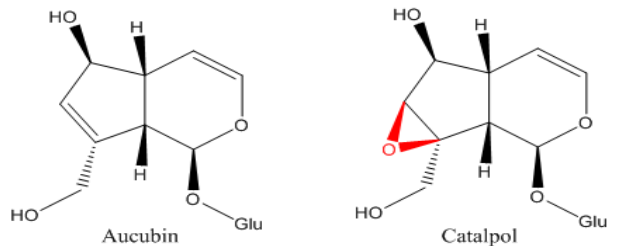

Fig. 2: Aucubin and catalpol structures

On the other hand, verbascoside is also one of the main active constituents of ribwort plantain as presented in (fig. 3), which has many pharmacological effects that include its role in the treatments 
of neurodegenerative disorders, pains and aches [21, 22], in addition to its antioxidant [23], antitumor [24, 25], anti-allergic and antiinflammatory effects [26-29].

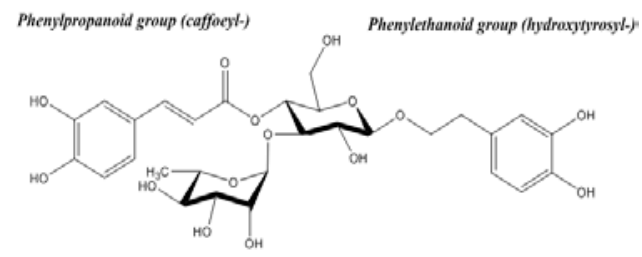

Fig. 3: Verbascoside

Medicinally, a tea of this plant can be used internally for its soothing effect and for treating many complaints involving: cough, bronchitis, sinusitis, asthma, diarrhea, gastritis, peptic ulcers, irritable bowel disease, internal bleeding, hemorrhoids, anal fissure, cervicitis and bladder inflammation [30-33]; externally, it is used in treating skin problems like ulcers, inflammations, stings, cuts, and bleeding [34]. Its astringent effect made this plant effective and safe for treatment of bleeding and inspires the healing of injured tissue [35].

The objective of this work was to determine, isolate and identify verbascoside and aucubin in Iraqi P. lanceoleta L. by using different chromatographic and spectrometric methods.

\section{MATERIALS AND METHODS}

\section{Plant material}

Young Plantago lanceoleta (fig. 1) was collected in the month of January/ 2018 from the medicinal plant garden of Mustinsirya University/College of Pharmacy, district of Al-Qadisiyah/Baghdad-Iraq. The sample was authenticated by Assist Prof. Ibrahim S. Abbas, Department of Pharmacognosy and Medicinal Plants, College of Pharmacy, Mustansiriya University, Baghdad-Iraq, voucher specimens were deposited in the National herbarium of Iraq (no. 52749). Collected sample was washed and cleaned directly by water to remove the dust and other debris; after that, the plant was dried at room temperature under a stream of air to avoid the fermentation. After drying, the plant was powdered and homogenized by automatic mortar; the powder kept in the securely closed container and stored at $4{ }^{\circ} \mathrm{C}$ for further studies.

\section{Chemicals and reagents}

Aucubin, catalpol and verbascoside standards were obtained from Sigma-Aldrich. Ammonia, Ethyl acetate, n-Hexane, and Methanol were provided by Sharlau Chemicals. Copper (ll) sulfate 5 hydrate, Formic acid, n-butanol, Sulfuric acid, and Trifluroacetic acid were obtained from BDH Chemicals. Anisaldehyde and Glacial acetic acid were supplied by Riedel-de Haen. All solvents and reagents that used were of analytical grade.

\section{Extraction of aucubin and verbascoside}

The leaves powder (20 gm) of Iraqi P. lanceoleta L. was defatted with n-hexane $(350 \mathrm{ml})$ by using soxhlet apparatus [36]. After that, absolute methanol was used as extracting solvent $(330 \mathrm{ml})$; the extraction conducting for about $12 \mathrm{~h}$. After that, the extract was concentrated and dried by using a rotatory vacuum evaporator at 50 ${ }^{\circ} \mathrm{C}$. The dry extract was saved in tightly sealed amber glass container under $4{ }^{\circ} \mathrm{C}$ until analysis time.

\section{General procedure}

The high-performance thin-layer chromatography (HPTLC) analysis was done on $60 \mathrm{GF} 254(10 * 10 \mathrm{~cm})$ glass HPTLC plates (Merck,
Germany) with $0.2 \mathrm{~mm}$ thickness; all samples and standards applied on the HPTLC plates automatically by means of thin-layer chromatography (TLC) sampler 3 (Camag, Switzerland), while densitograms were gained by use of TLC Scanner 3, using WinCat software (Camag, Switzerland). Preparative TLC plates that used for isolation were coated with silica gel GF 254 with dimensions of $(20$ * $20 \mathrm{~cm}$ ) and thickness of $0.5 \mathrm{~mm}$. 6410 Series LC system was used (Agilent technologies, Germany); the separation by liquid chromatography-mass spectrometry (LC-MS) was done by Zobrex C18 analytical column with length of $150 \mathrm{~mm}$, diameter of $4.6 \mathrm{~mm}$ and particle size of $5 \mu \mathrm{m}$. The infrared (IR) spectrum of aucubin was obtained using $\mathrm{KBr}$ disk on foureir-transform (FT-IR) JASCO, 6100.

\section{Chromatographic analysis for detection of aucubin and} verbascoside

\section{TLC analysis}

A small amount of methanolic extract was dissolved in water, filtered and cleaned-up by partitioning the aqueous layer with ethyl acetate (ETAC) (this partitioning did not used for verbascoside due to its moderate solubility in ethyl acetate), the water layer was used for the TLC analysis of aucubin.

Three mobile phases were used for the analytical TLC of aucubin including n-butanol (n-BuOH): distilled water (DW) in a proportion of $9 \mathrm{ml}: 1 \mathrm{ml}$ [37], n-BuOH: acetic acid (AcOH): DW (8 ml: $2 \mathrm{ml}: 10$ $\mathrm{ml}$ ) and isopropanol (IsoPrOH): DW (6 ml: $4 \mathrm{ml}$ ) [38]. Three mobile phases were used for the analytical TLC of verbascoside including Ethyl acetate (ETAC): methanol (MeOH): DW (77 ml: $15 \mathrm{ml}: 8 \mathrm{ml})$ [39], ETAC: DW: formic acid (FA) $(10 \mathrm{ml}: 3 \mathrm{ml}: 2 \mathrm{ml})$ and ETAC: MeOH: DW (100 ml: $16.5 \mathrm{ml}: 13.5 \mathrm{ml}$ [ [40, 41].

The solvent system that used for isolation of aucubin by preparative TLC was n-BuOH: DW (9:1); while ETAC: MeOH: DW (77:15:8) was used as a mobile phase for isolation of verbascoside. The dry methanolic extract $(0.5 \mathrm{gm})$ was dissolved in water and partitioned with ETAC, and both layers were subjected to Trim-Hill test; after that, the concentrated solution applied on the TLC plates for isolation of aucubin; the same amount was dissolved in methanol and applied on the TLC plates for isolation of verbascoside without the partitioning step due to the solubility of verbascoside in the ethyl acetate. Therefore, the cleaning-up step was done by applying TLCisolated verbascoside again on the TLC plates for maximum purity.

Derivatization with other compound is necessary for visualization of aucubin spot. So, two reagents were used for post-derivatization of aucubin that includes $10 \%$ alcoholic $\mathrm{H}_{2} \mathrm{SO}_{4}$ which burns the glucose molecule in the aucubin giving colored spot and $10 \%$ anisaldehyde that gives a colored spot for aucubin molecule [41, 42]. These reagents were applied by dipping TLC plates in the reagent solutions or by spraying the solutions on the TLC plates

\section{HPTLC analysis}

The solvent systems that used for HPTLC analysis were chloroform $\left(\mathrm{CHCl}_{3}\right)$ : $\mathrm{MeOH}$ : 0.25M trifluoroacetic acid in ammonia (7:4:1) and ETAC: MeOH: DW (77:15:8) for separating aucubin and verbascoside, respectively.

\section{Liquid chromatography-mass spectrometry (LC-MS) analysis Detection of aucubin and catalpol}

LC-MS conditions: LC-MS analysis was accomplished in the Shahid Bahashti University/College of Pharmacy in Iran; the mobile phase was consisted of acetonitrile (ACN) and water at $0.5 \mathrm{ml} / \mathrm{min}$ flow rate, with 20 min running time; the volume of injection was $25 \mu \mathrm{L}$ at ambient temperature; the gradient elution program is presented in (table 1).

Table 1: Gradient elution program

\begin{tabular}{ll}
\hline Time (min) & Mobile phase fraction (\% ACN) \\
\hline 0 & 95 \\
4 & 95 \\
8 & 10 \\
12 & 10 \\
16 & 95 \\
20 & 95 \\
\hline
\end{tabular}


After that, $1 \%$ of acetic acid in sodium acetate $200 \mu \mathrm{M}$ and water at $0.07 \mathrm{ml} / \mathrm{min}$ flow rate was added. The mass spectrometer was triple quadrupole, that worked in the electrospray positive ionization mode (ESI+), which set for isolating the sodium ions of catalpol and aucubin with mass to size ratio (m/z) of 384 and 368 respectively; the full scan was done in $\mathrm{m} / \mathrm{z}$ range of 200-800 Dalton. The pressure of nebulizer was $60 \mathrm{psi} \mathrm{N} 2$ at $12 \mathrm{~L} / \mathrm{min}$; the voltage of fragmentor was set at $65 \mathrm{~V}$ and the capillary voltage was $4000 \mathrm{~V}$.

\section{Detection of verbascoside}

\section{LC condition}

The same instrument was used with different parameters; column: ZORBOX ODS (4.6 X150 mm, $5 \mu \mathrm{m}$ ); column temperature $25^{\circ} \mathrm{C}$; Mobile phase: $\mathrm{A}=0.1 \%$ acetic acid (aqueous sol), $\mathrm{B}=0.1 \%$ acetic acid (acetonitrile solution), (A: B) = 20:80; flow rate: $0.3 \mathrm{ml} / \mathrm{min}$; injection volumes were $10 \mu \mathrm{l}$.

\section{MS condition}

The mode was negative electrospray ionization (ESI-) using the Agilent G6410 Triple Quadrupole Mass spectrometer; nebulizer = 15 psi; drying gas flow $=6 \mathrm{ml} / \mathrm{min} ; \mathrm{V}$ capillary $=4000 \mathrm{v}$; drying gas temperature: 300 ${ }^{\circ} \mathrm{C}$; Dwell time: $500 \mathrm{msec}$; fragment or voltage $=135 \mathrm{v}$.

\section{FT-IR analysis of TLC-isolated aucubin}

The analysis was done in Shahid Beheshti University/College of Pharmacy in Iran. TLC-isolated aucubin was subjected to FT-IR analysis for observing some of the important functional groups in the compound; the sample of aucubin was in the solid state $(2$ $\mathrm{mg}$ ) that mixed with perfectly dried $\mathrm{KBr}(150 \mathrm{mg})$, which then mulled together by mortar and pestle for producing small particle size for avoiding the Christiansen effect [43].

\section{RESULTS}

Aucubin and verbascoside were analyzed by TLC with their analytical standards in three different mobile phases for each one, and compared with that reported in the literatures. For aucubin, only the aqueous layer gave a positive result in TrimHill test; all TLC tests revealed the presence of both compounds in the plant samples; $10 \%$ alcoholic $\mathrm{H}_{2} \mathrm{SO}_{4}$ solution was gave the best result; the best method for applying the visualizing reagent was dipping the plate in the solution, as shown in (table 2).

Table 2: $\boldsymbol{R}_{f}$ values for aucubin and verbascoside in different mobile phases

\begin{tabular}{|c|c|c|c|c|c|}
\hline \multirow[t]{2}{*}{ Mobile phases } & \multicolumn{2}{|c|}{$R_{f}$ values of Aucubin } & \multirow[t]{2}{*}{ Mobile phases } & \multicolumn{2}{|c|}{$R_{f}$ values of verbascoside } \\
\hline & Sample & Standard & & Sample & Standard \\
\hline n-BuOH: DW 9:1 & 0.55 & 0.57 & ETAC: MeOH: DW 77:15:8 & 0.62 & 0.60 \\
\hline n-BuOH: conc. AcOH: DW 4:1:5 & 0.36 & 0.35 & ETAC: DW: FA 10:3:2 & 0.65 & 0.64 \\
\hline IsoPrOH: DW 6:4 & 0.78 & 0.79 & ETAC: MeOH: DW 100:16.5:13.5 & 0.55 & 0.56 \\
\hline
\end{tabular}

It was found that the dry powder of Iraqi $P$. lanceoleta $L$. leaves (young plant) contain 1.74 percent of verbascoside, making this plant a rich source for verbascoside; while the isolated aucubin was found to be 0.24 percent of the powdered plant material; the preparative TLC fig. is presented in (fig. 3).

The development of HPTLC plates for aucubin accomplished after 45 min; then the plates dried by an electrical dryer and dipped in alcoholic $\mathrm{H}_{2} \mathrm{SO}_{4}$ (10\%) and then dried for visualizing the spots, as shown in (fig. 4B). The development of HPTLC plate for verbascoside accomplished after $35 \mathrm{~min}$; then the plate dried by an electrical dryer and visualized under UV light $(365 \mathrm{~nm})$, as presented in (fig. $4 \mathrm{~A})$.

Both aucubin and catalpol (M. W 346.3 and 362.3 respectively) were separated by LC and detected in Iraqi $P$. lanceoleta $\mathrm{L}$. by electrospray ionization mass spectroscopy (ESI-MS) in the positive mode (ESI+) as sodium adducts $\left[\mathrm{M}+\mathrm{Na}^{+2}\right]$ as presented in the (fig. 5).

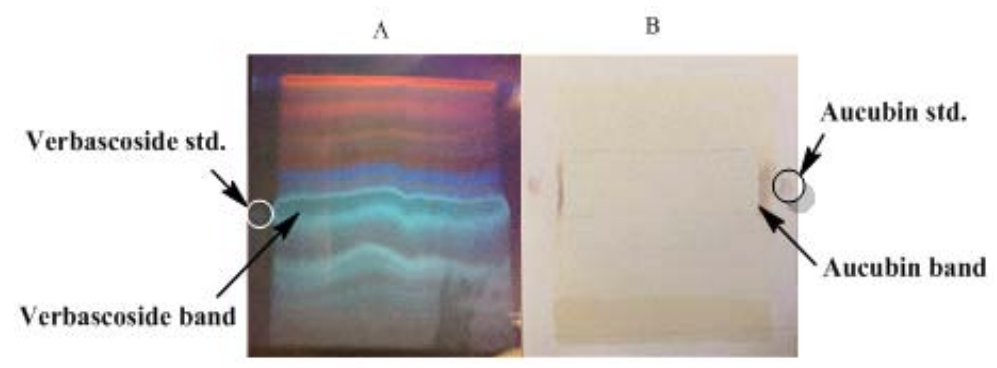

Fig. 3: Preparative TLC (A isolation of verbascoside, B isolation of aucubin)

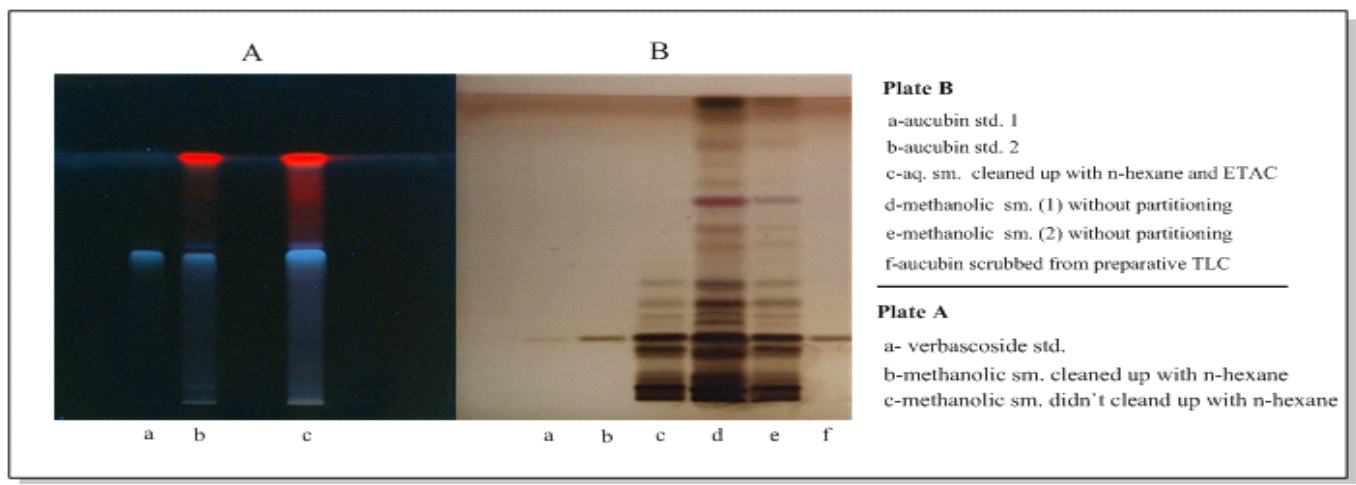

Fig. 4: HPTLC plates for qualitative studies of aucubin and verbascoside in Iraqi P. lanceoleta $L$. 


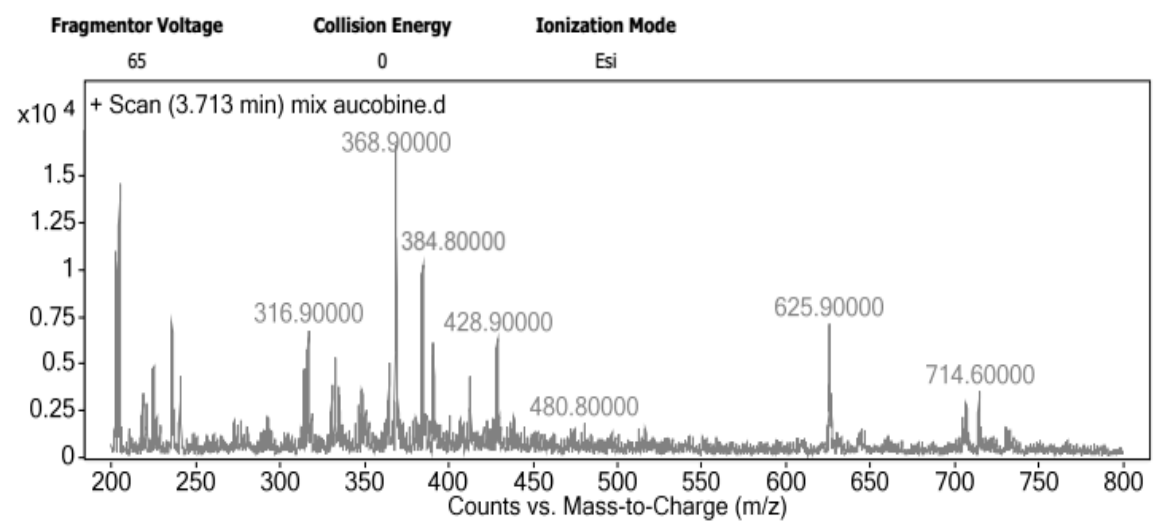

Fig. 5: Determination of aucubin and catalpol in the Iraqi P. lanceoleta L. by LC-MS analysis

Verbascoside (M. W 624.2) was determined in the Iraqi P. lanceoleta L. by means of LC-MS analysis using ESI-MS in negative ionization mode (ESI-) as quasi-molecular ion $\left[\mathrm{M}-\mathrm{H}^{+}\right]$; which gave the mother ion $\left[\mathrm{M}-\mathrm{H}^{+}\right]$with two product ions, as presented in (fig. 6).

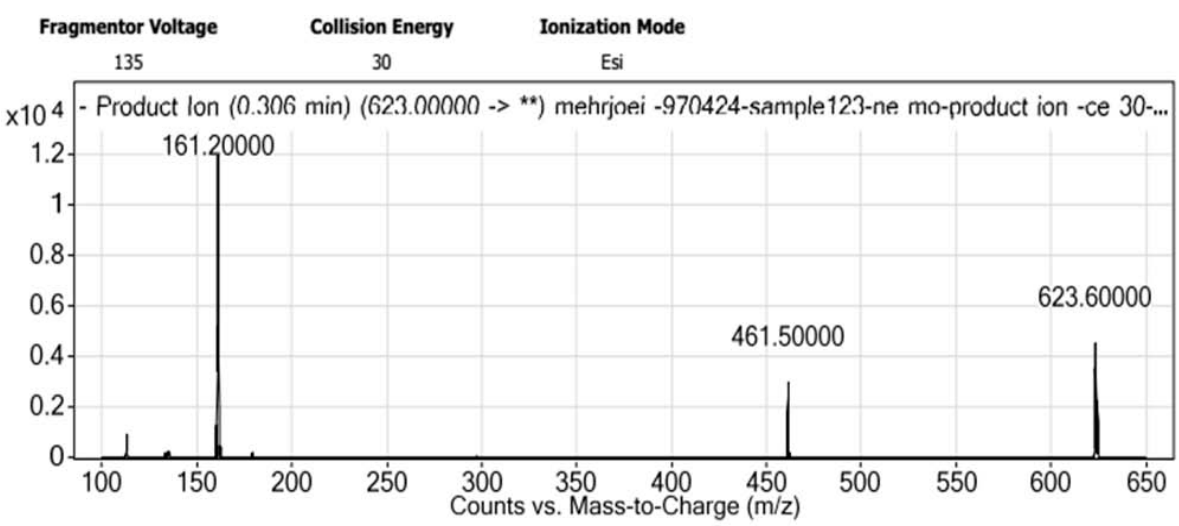

Fig. 6: Determination of verbascoside in the Iraqi P. lanceoleta $L$.

Verbascoside that isolated from the preparative TLC plates was also analyzed and compared to that detected in the plant sample; the result shown the high purity of verbascoside that cleared-up by preparative TLC, as clarified in (fig. 7).

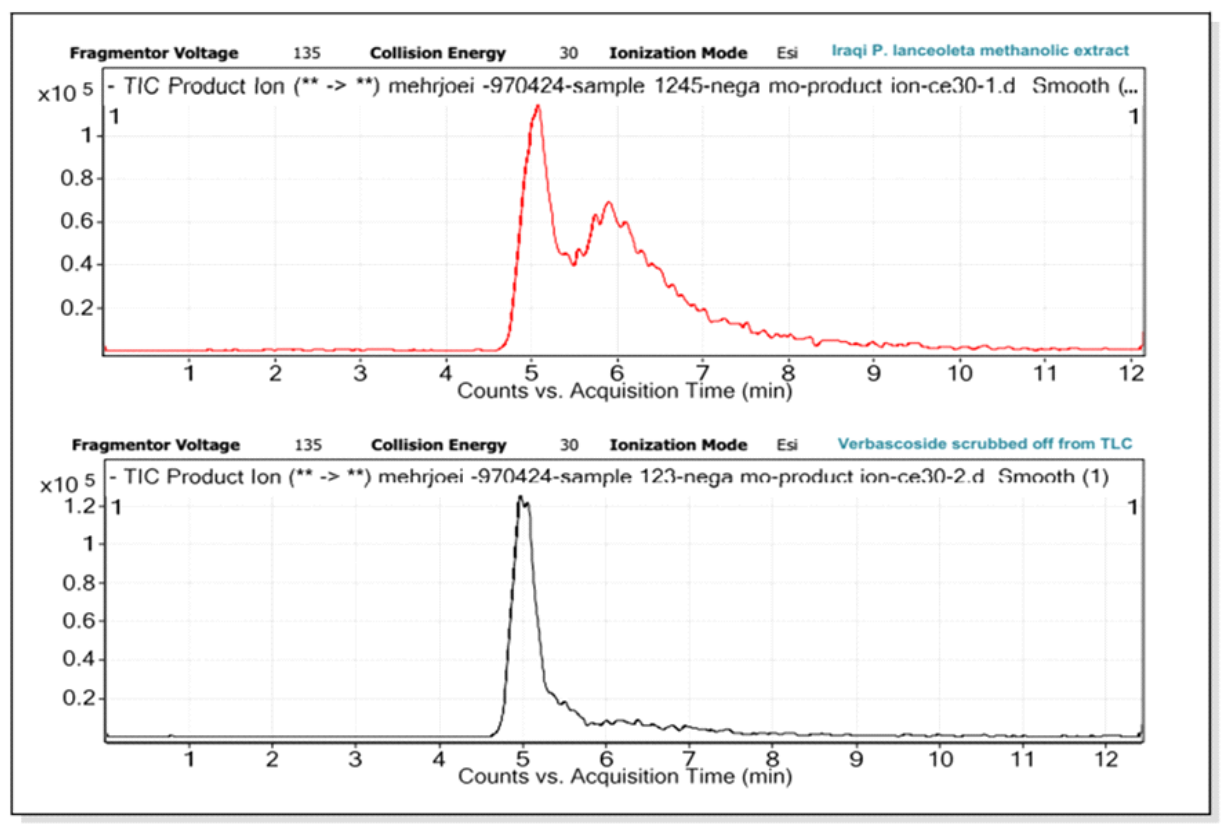

Fig. 7: Plant sample vs. TLC-isolated verbascosideunder LC-MS 
After confirming its purity by HPTLC chromatography [44-46], TLCisolatedaucubin was subjected to FT-IR analysis, in which the absorption of many important functional groups of aucubin was observed, as shown in (fig. 8) and (table 3).

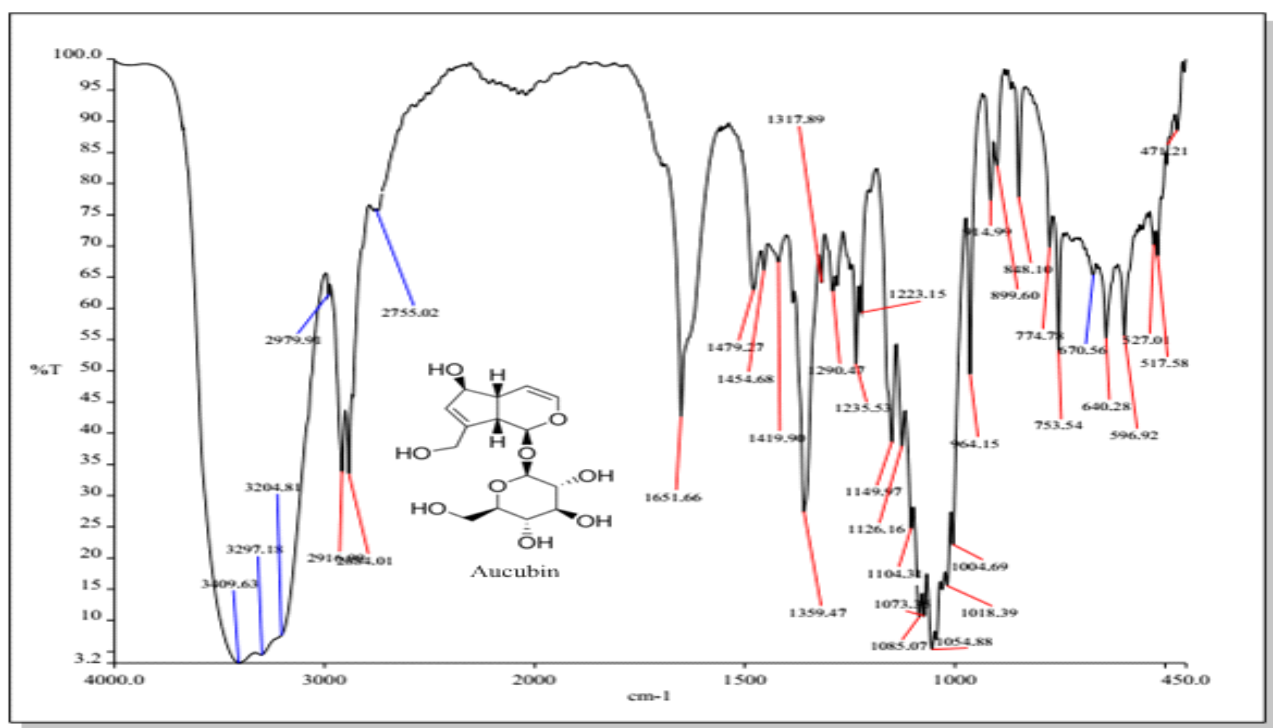

Fig. 8: FT-IR analysis of the aucubin isolated from Iraqi P. lanceoleta L. by TLC

Table 3: IR absorption of some important functional groups observed in the IR chart of the aucubin isolated from Iraqi $P$. Ianceoleta $\mathrm{L}$.

\begin{tabular}{lll}
\hline Functional group & Absorption (cm-1) & Intensity \\
\hline O-H of $1^{\circ}$ and $2^{\circ}$ alcohol & $3409-3204$ & Broad, strong \\
C=C of alkene & 1651 & Sharp, medium \\
Alcoholic O-H & 1359 & Sharp, medium \\
C-O of ether & 1126 & Stretchion \\
Alcoholic C-O & 1054 & Sharp, medium \\
\hline
\end{tabular}

\section{DISCUSSION}

From the above findings, 1.74 percent of verbascoside obtained from Iraqi P. lanceoleta L. in first growing season considered as high percent and compatible to that highlighted in British pharmacopeia "P. lanceoleta L. contains 1.5 percent of verbascoside as minimum", while another study showed that the $P$. lanceolate $\mathrm{L}$. cultivated in New Zealand showed an increment in the concentration of verbascoside from 2.36 to 3.54 percent in the first growing season, which is higher than that obtained from Iraqi plant; the same study showed an increment in aucubin concentration from 0.178 to 0.380 percent which is compatible to that obtained from Iraqi plant (0.240 percent) [13].

Post-derivatization with the specific reagent is essential for visualization of aucubin spot because there is no any chromophore in aucubin molecule. Verbascoside on another hand, its molecule contains two chromophores with many auxochromes attached to both chromophores; these properties of verbascoside molecule allow it to be seen under UV lamp (254 and $365 \mathrm{~nm}$ ).

The result of LC-MS showed that the difference in the molecular weight of aucubin and catalpol sodium adducts was 16 Dalton, due to the difference in one oxygen atom, as presented in (fig. 5). The LC-MS result for verbascoside showed two daughter ions with high abundance at $\mathrm{m} / \mathrm{z} 461.5$ and 161.2, that resulted from the loss of a hexose sugar moiety $\left[\mathrm{M}-\mathrm{H}^{+}-162\right]$ and loss of water molecule from the caffoeyl moiety (weak fragment at $179 \mathrm{~m} / \mathrm{z}$ ), respectively. The LC-MS result also showed the high purity of TLC-isolated verbascoside compared to that detected in the P. lanceoleta $\mathrm{L}$. extract.

The FT-IR result for aucubin showed that $\mathrm{C}=\mathrm{C}$ stretch result in the generation of the most characteristic peak in the aucubin structure, which occurs at $1651 \mathrm{~cm}^{-1}$, unlike the conjugated or aromatic $\mathrm{C}=\mathrm{C}$, which their absorptions occur at lower frequencies in the range of $1630-1600 \mathrm{~cm}^{-1}[47]$.

\section{CONCLUSION}

All the results (e. g. TLC, HPTLC, LC-MS, FT-IR) proved the presence of aucubin and verbasoside in the Iraqi $P$. lanceoleta L.; the plant showed a high content $(1.74 \%)$ of verbasoside. Therefore, it is considered as a very rich source for this compound, which can easily be isolated from the Iraqi $P$. lanceoleta $\mathrm{L}$. and subjected to numerous pharmacological studies. The extract of the young leaves of this plant gave $0.24 \%$ of aucubin, and it is easy to obtain a higher percent from the older leaves to be a source for an important compound that needs more attention and pharmacological studies.

\section{ACKNOWLEDGMENT}

The authors are very gratitude to the Mustinsirya University/College of Pharmacy for providing the facilities for the achievement of this work. We are very grateful to Shahid Bahashti University/College of Pharmacy in Iran for their collaboration in the success of this work

\section{AUTHORS CONTRIBUTIONS}

Hasan A. Khalaf was responsible for HPTLC and advanced chemical analysis, including liquid chromatography-mass spectrometry (LCMS) and fourier-transform infrared spectroscopy (FT-IR). Assist Prof. Dr. Ibrahim S. Abbas was responsible for authentication, collection, and drying of the plant. Amani A. Tawfeeq was responsible for plant extraction and isolation of active constituents. Prof. Dr. Monther F. Mahdi was responsible for an explanation of the results and revision of the manuscript.

\section{CONFLICT OF INTERESTS}

\section{Declared none}

\section{REFERENCES}

1. Tack AJ, Laine AL. Ecological and evolutionary implications of spatial heterogeneity during the off-season for a wild plant pathogen. New Phytol 2014;202:297-308. 
2. Stewart AV. Plantain (Plantagolanceolata) potential pasture species. In: Proceedings of the Conference-New Zealand Grassland Association; 1996. p. 77-86.

3. Lukova P, Iliev I, Nikolova M. Comparative morphological and qualitative pharmaceutical analysis of plantago media L. leaves with P. major L. and P. lanceoleta L. leaves. IJMRPS 2017;4:20-5.

4. Grigore A, Bubueanu C, Pirvu L, Ionita L, Toba G. Plantagolanceolata L. crops-source of valuble raw material for various industrial applications. Sci Papers Series A Agronomy 2015;58:207-14.

5. Handjieva N, Saadi H, Evstatieva L. Iridoid glueosides from Plantagoaltissima L., Plantagolanceolata L., Plantagoatrata Hoppe and Plantagoargentea Chaix. Z. Naturforsch C Bio Sci 1991;46:963-5.

6. Maksyutina NP. Hydroxycinnamic acids of Plantago major and P. lanceolata. Chem Nat Compd 1971;7:795.

7. Murai M, Tamayama Y, Nishibe S. Phenylethanoids in the herb of Plantagolanceolata and inhibitory effect on arachidonic acidinduced mouse ear edema. Planta Med 1995;6:479-80.

8. Bräutigam M, Franz G. Structural features of Plantagolanceolata mucilage. Planta Med 1985;51:293-7.

9. Wichtl M. Herbal drugs and phytopharmaceuticals: a handbook for practice on a scientific basis, 3rd edition. Medpharm $\mathrm{GmbH}$ Scientific Publishers; 2004. p. 456-60.

10. Haznagy A. Recent results with plantaginis folium (Plantain leaves). Herba Hung 1970;9:57-63.

11. Fons F, Rapior S, Gargadennec A, Andary C, Bessiere JM. Volatile components of Plantago lanceolata (Plantaginaceae). Acta Bot Gall 1998;145:265-9.

12. Rymkiewicz A. Studies on the species of the genus Plantago L. with reference to carpology and chemotaxonomy. Monogr Bot 1979;57:71-103.

13. Navarrete S, Kemp PD, Pain SJ, Back PJ. Bioactive compounds, aucubin, and acteoside, in plantain (Plantagolanceolata L.) and their effect on in vitro rumen fermentation. Anim Feed Sci Technol 2016;222:158-67.

14. Yang KH, Kwon TJ, Choe SY, Yun HS, Chang IM. Protective effect of Aucuba japonica against carbon tetrachloride-induced liver damage in rats. Drug Chemtoxicol 1983;6:429-41.

15. Jin L, Xue HY, Jin LJ, Li SY, Xu YP. Antioxidant and pancreasprotective effect of aucubin on rats with streptozotocininduced diabetes. Eur J Pharmacol 2008;582:162-7.

16. Wang SN, Xie GP, Qin CH, Chen YR, Zhang KR. Aucubin prevents interleukin-1 beta-induced inflammation and cartilage matrix degradation via inhibition of $\mathrm{NF}-\mathrm{KB}$ signaling pathway in rat articular chondrocytes. Int Immunopharmacol 2015;24:408-15.

17. Urbina AO, Martin ML, Fernandez B, San Roman L, Cubillo L. In vitro antispasmodic activity of peracetylatedpenstemonoside, aucubin and catalpol. Planta Med 1994;60:512-5.

18. Li Y, Sato T, Metori K, Koike K, Che QM, Takahashi S. The promoting effects of geniposidic acid and aucubin in Eucommiaulmoides oliver leaves on collagen synthesis. Biological Pharm Bull 1998;21:1306-10.

19. Kim YM, Sim U, Shin Y, Kim Kwon Y. Aucubin promotes neurite outgrowth in neural stem cells and axonal regeneration in sciatic nerves. Experimental Neurobiol 2014;23:238-45.

20. Park KS. Aucubin, a naturally occurring iridoid glycoside inhibits TNF- $\alpha$-induced inflammatory responses through suppression of NF- $\kappa$ B activation in 3T3-L1 adipocytes. Cytokine 2013;62:407-12.

21. Wang HQ, Xu YX, Zhu CQ. Upregulation of heme oxygenase-1 by acteoside through ERK and PI3 K/Akt pathway confer neuroprotection against beta-amyloid-induced neurotoxicity. Neurotoxic Res 2012;21:368-78.

22. Filho AG, Morel AF, Adolpho L, Ilha V, Giralt E, Tarrago T, et al. Inhibitory effect of verbascoside isolated from Buddlejabrasiliensis Jacq. Ex Spreng on prolyl oligopeptidase activity. Phytother Res 2012;26:1472-5.

23. Quirantes Pine R, Herranz Lopez M, Funes L, Borras Linares I, Micol V, Segura Carretero A, et al. Phenylpropanoids and their metabolites are the major compounds responsible for bloodcell protection against oxidative stress after administration of Lippiacitriodora in rats. Phytomedicine 2013;20:1112-8.

24. Zhang F, Jia Z, Deng Z, Wei Y, Zheng R, Yu L. In vitro modulation of telomerase activity, telomere length and cell cycle in MKN45 cells by verbascoside. Planta Med 2002;68:115-8.
25. Lee KW, Kim HJ, Lee YS, Park HJ, Choi JW, Ha J, et al. Acteoside inhibits human promyelocytic HL-60 leukemia cell proliferation via inducing cell cycle arrest at G 0/G 1 phase and differentiation into monocyte. Carcinogenesis 2007;28:1928-36.

26. Lee JH, Lee JY, Kang HS, Jeong CH, Moon $\mathrm{H}$, Whang WK, et al. The effect of acteoside on histamine release and arachidonic acid release in RBL-2H3 mast cells. Arch Pharm Res 2006;29:508

27. Song HS, Choi MY, Ko MS, Jeong JM, Kim YH, Jang BH, et al. Competitive inhibition of cytosolic $\mathrm{Ca}^{2+}$-dependent phospholipase A 2 by acteoside in RBL-2H3 cells. Arch Pharm Res 2012;35:905-10.

28. Pastore S, Potapovich A, Kostyuk V, Mariani V, Lulli D, De Luca $\mathrm{C}$, et al. Plant polyphenols effectively protect HaCaT cells from ultraviolet C-triggered necrosis and suppress inflammatory chemokine expression. Ann N Y Acad Sci 2009;1171:305-13.

29. Korkina L, Kostyuk V, De Luca C, Pastore S. Plant phenylpropanoids as emerging anti-inflammatory agents. Mini Rev Med Chem 2011;11:823-35.

30. Tita I, Mogosanu GD, Tita MG. Ethnobotanical inventory of medicinal plants from the South-West of Romania. Farmacia 2009;57:141-56.

31. Neves JM, Matos C, Moutinho C, Queiroz G, Gomes LR. Ethnopharmacological notes about ancient uses of medicinal plants in trás-os-montes (northern of Portugal). J Ethnopharmacol 2009;124:270-83.

32. Kültür Ş. Medicinal plants used in Kırklareli province (Turkey). J Ethnopharmacol 2007;111:341-64.

33. Kuhn MA, Winston D. Herbal therapy and supplements: a scientific and traditional approach. Lippincott Williams and Wilkins; 2000. p. 262.

34. Farahpour MR, Heydari A. Wound healing effect of the hydroethanolic extract of ribwort plantain leaves in rabbits. Res Opin Anim Vet Sci 2015;5:143-7.

35. Yasari E, Vahedi A. Study of iranian biospherical reservation areas for medicinal plants diversity. World Acad Sci Eng Tech Int J Biomed Biol Eng 2011;5:53-6.

36. Salwe KI, Sachdev DE. Evaluation of the antinociceptive and anti-inflammatory effect of the hydroalcoholic extracts of leaves and fruit peel of P. granatum in experimental animals. Asian J Pharm Clin Res 2014;7:137-41.

37. Ibrahim NA, El-Hawary SS, Ali SA, Mohammed MMD, Refaat EE. Chemical constituents of Paulownia tomentosa (thunb). FAM. Scrophulariaceae and its role against *hyperglycemia. World J Pharm Res 2015;4:2445-66.

38. Harborne JB. Phytochemical methods: a guide to modern techniques of plant analysis. London, Champman, and Hall; 1973. p. 100.

39. Kemper FH. Chromatographic fingerprint analysis of herbal medicines: thin-layer and high-performance liquid chromatography of Chinese drugs. Phytomedicine 2011;18:431-2.

40. Sarkhail P, Nikan M, Sarkheil P, Gohari AR, Ajani Y, Hosseini R, et al. Quantification of verbascoside in medicinal species of phlomis and their genetic relationships. DARU 2014;22:32.

41. Frum Y, Viljoen AM, Van Heerden FR. Verbascoside and luteolin-5-0- $\beta$-D-glucoside isolated from Hallerialucida L. exhibit antagonistic anti-oxidant properties in vitro. S Afr J Bot 2007;73:583-7.

42. Jang SS, Shirai Y, Uchida M, Wakisaka M. Production of mono sugar from acid hydrolysis of seaweed. Afr J Biotechnol 2012;11:1953-63.

43. Franz M, Fischer BM, Walther M. The christiansen effect in terahertz time-domain spectra of coarse-grained powders. Appl Phys Lett 2008;92:21107.

44. Pal P, Singh SB, Singh A. Determination of physiochemical properties, antioxidant constituents by high-performance thin layer chromatography fingerprinting, and antioxidant activity of Cucurbita maxima seeds. Asian J Pharm Clin Res 2018;11:280-3.

45. Rajamani M, Krishnasamy K, Abubakker N. High-performance thin layer chromatography analysis and free radical scavenging potential of south Indian orthodox black tea. Asian J Pharm Clin Res 2018;11:449-55. 
46. Orth HC, Rentel C, Schmidt PC. Isolation, purity analysis and stability of hyperforin as a standard material from Hypericumperforatum L. J Pharm Pharmacol 1999;51:193-200.
47. Silverstein RM, Webster FX, Kiemle DJ, Bryce DL. Spectrometric identification of organic compounds. 7 th Ed. John Wileyand Sons; 2014. p. 70-110. 